\title{
The Green Dialysis Survey: Establishing a Baseline for Environmental Sustainability across Dialysis Facilities in Victoria, Australia
}

\author{
Katherine A Barraclough ${ }^{1,2}$, Alice Gleeson ${ }^{2}$, Stephen G Holt ${ }^{1,2}$, John WM Agar ${ }^{3}$ \\ ${ }^{1}$ Department of Nephrology, Royal Melbourne Hospital, Parkville, Australia; \\ ${ }^{2}$ Victorian Renal Clinical Network, Safer Care Victoria, Department of Health and \\ Human Services, Melbourne, Australia; \\ ${ }^{3}$ Department of Renal Medicine, University Hospital Geelong, Barwon Health, \\ Geelong, Australia.
}

\section{Address for Correspondence and Reprints}

Dr. Katherine Barraclough

Department of Nephrology, Royal Melbourne Hospital

300 Grattan Street, Parkville, VIC 3050

Email: Katherine.barraclough@mh.org.au

Ph: +61393457058 or +61411349961

Fax: +61393471420

\section{Short title}

The Green Dialysis Survey

This is the author manuscript accepted for publication and has undergone full peer review but has not been through the copyediting, typesetting, pagination and proofreading process, which may lead to differences between this version and the Version of Record. Please cite this article as doi: 10.1111/nep.13191

This article is protected by copyright. All rights reserved. 


\section{ABSTRACT}

Aim: The Green Dialysis Survey aimed to 1) establish a baseline for environmental sustainability (ES) across Victorian dialysis facilities, and 2) guide future initiatives to reduce the environmental impact of dialysis delivery.

Methods: Nurse unit managers of all Victorian public dialysis facilities received an online link to the survey, which asked 107 questions relevant to the ES of dialysis services.

Results: Responses were received from 71/83 dialysis facilities in Victoria (86\%), representing 628/660 dialysis chairs (95\%). Low energy lighting was present in 13 facilities (18\%), $18(25 \%)$ recycled reverse osmosis water and $7(10 \%)$ reported use of renewable energy. Fifty-six facilities (79\%) performed comingled recycling but only $27(38 \%)$ recycled polyvinyl chloride plastic. A minority educated staff in appropriate waste management $(n=30 ; 42 \%)$ or formally audited waste generation and segregation $(n=19 ; 27 \%)$. Forty-four $(62 \%)$ provided secure bicycle parking but only $33(46 \%)$ provided shower and changing facilities. There was limited use of tele- or video-conferencing to replace staff meetings ( $n=19 ; 27 \%)$ or patient clinic visits $(n=13 ; 18 \%)$. A minority considered ES in procurement decisions $(n=28 ; 39 \%)$ and there was minimal preparedness to cope with climate change. Only 39 services $(49 \%)$ confirmed an ES policy and few had ever formed a green group $(n=14 ; 20 \%)$ or were currently undertaking a green project $(n=8 ; 11 \%)$. Only 15 facilities $(21 \%)$ made formal efforts to raise awareness of ES.

Conclusions: This survey provides a baseline for practices that potentially impact the environmental sustainability of dialysis units in Victoria, Australia. It also identifies achievable targets for attention.

\section{KEY WORDS}

Dialysis, environment, resources, sustainability 


\section{INTRODUCTION}

Anthropogenic (human induced) climate change has been identified as the greatest global health threat of the 21 st century (1). However, healthcare itself contributes significantly to greenhouse gas emissions and depletion of natural resources. In the United Kingdom (UK), the National Health Service produces $\sim 4 \%$ of total carbon dioxide (CO2) emissions (2). In the United States (US) this figure is $>8 \%$ (3). Although similar nationwide data do not exist for Australia, public hospitals in Victoria consume $\sim 60 \%$ of the total energy used by state government departments, generate waste equivalent to 200,000 households, and use $1 \%$ of state water (4).

Dialysis programs have a particularly large carbon footprint (CFP), with a recurrent, per capita resource consumption and waste generation profile that appears disproportionally high compared to most other medical therapies (5). One Australian study has estimated the perpatient annual CFP of conventional haemodialysis $(\mathrm{HD})$ at $\sim 10.2$ tonnes CO2-equivalents ( $t$ CO2-eq) (6) - more than twenty times the mean per patient CFP in UK healthcare of $0.426 \mathrm{t}$ CO2-eq (7). The financial cost of treating end-stage kidney disease over the period 2009 to 2020 has been estimated at $\$ 12$ billion to the Australian Government (8).

As national and global efforts to combat climate change increase, it is likely that ever more regulatory and community pressures will force health systems, including dialysis services, to reduce carbon usage and conserve resources. Simultaneously, it will be essential to consider targeted actions to reduce costs if the current quality of care is to be maintained or improved in the face of ever-growing service demands (9).

Recognising that environmental initiatives might simultaneously address both carbon usage and cost, the Victorian Renal Clinical Network, now part of Safer Care Victoria in the Department of Health and Human Services, established an Environmental Sustainability Special Interest Group (ESSIG) in 2016 to encourage sustainable delivery of dialysis. The ESSIG initiated the GREENS survey to: 1) establish a baseline for environmental sustainability across Victorian dialysis services, and 2) guide future initiatives to reduce the environmental impact of dialysis delivery.

\section{METHODOLOGY}

This article is protected by copyright. All rights reserved. 
The ESSIG survey used an on-line, cloud-based software platform, SurveyMonkey, to ask 107 questions relevant to the environmental sustainability of dialysis services. Particular emphasis was placed on energy and water use, waste management, consumption and procurement of resources, patient and staff transport, and building design. The survey also requested information about environmental policies, improvement initiatives, attitudes towards environmental sustainability and climate change preparedness.

Nurse unit managers of all Victorian public dialysis facilities received an email link to the survey and were asked to either complete it themselves or appropriately delegate it. To maximise response rate, a reminder email was sent and a follow-up phone call made to any unit that failed to complete the survey.

\section{RESULTS}

Responses were received from 71 of 83 dialysis facilities in Victoria (86\%). These included 9 in-centre haemodialysis facilities, 51 satellite haemodialysis facilities, 6 stand-alone home therapy facilities (these cared for both home haemodialysis and peritoneal dialysis patients) and 7 facilities that co-located in-centre and home therapy services. In total, 628 of 660 Victorian haemodialysis chairs (95\%) and all home therapy facilities were represented in the survey responses.

Not all respondents answered every question. To aid interpretation of data, both the number of responses to each question and the percentage of those responding out of the total number of respondents are presented.

\section{Building Energy Use}

\subsection{Lighting}

Of the 71 responding facilities, $13(18 \%)$ predominantly used low energy light emitting diode bulbs; $36(51 \%)$ predominantly used fluorescent lighting; and $10(14 \%)$ were unsure of the type of lighting used. There was limited use of motion sensors, with $47(66 \%)$ indicating these were 'not present anywhere' in their facility.

\subsection{Heating and cooling}

Only 47 respondents $(66 \%)$ felt that appropriate ambient temperatures were maintained in their facilities, with nearly half ( $n=33 ; 46 \%)$ having no access to thermostats. Summer shading was provided for north-facing windows in 44 facilities (62\%).

This article is protected by copyright. All rights reserved. 


\subsection{Electrical equipment}

Fifty-five facilities $(77 \%)$ indicated that staff were encouraged to shut down computers when not in use, with a similar number $(n=58 ; 82 \%)$ reporting that inactive computers and photocopiers were auto-configured to enter hibernation, sleep or standby mode.

\subsection{Energy}

Almost half the facilities ( $n=31 ; 44 \%)$ were unsure of their energy source. Of those 'aware', most used fossil fuel derived energy $(n=26 ; 37 \%)$, with only $7(10 \%)$ reporting use of energy from renewable sources (solar in all cases). Thirty-two (45\%) were unaware of their energy provider while most of the remainder were supplied energy by Origin, AGL or Energy Australia.

\section{Water}

Only 18 facilities (25\%) indicated that they recycled reverse osmosis (RO) reject water for use elsewhere (e.g. to flush toilets or water gardens). Similarly, only 17 (24\%) harvested roof rainwater for reuse. Water-saving taps were not present in any sinks in over a quarter of facilities $(n=20,28 \%)$ and present in only a few sinks in eight facilities (11\%).

\section{Waste}

Over three quarters of facilities $(n=56 ; 79 \%)$ offered appropriate bins for hard plastic (e.g. concentrate bottles), paper and cardboard recycling, but fewer $(n=27 ; 38 \%)$ recycled polyvinyl chloride (PVC) plastic. Twenty-seven facilities $(38 \%)$ indicated that they were able to recycle soft plastics other than PVC. Only 11 facilities (15\%) indicated that the suppliers of dialysis products took back pallets and cardboard boxes on delivery.

Although most facilities described their recycling efforts as 'good' or 'moderately good' ( $n=48$; $68 \%)$, only a minority actually educated staff in appropriate waste management $(n=30 ; 42 \%)$ or had ever formally audited waste generation or segregation $(n=19 ; 27 \%)$.

\section{Transport}

Forty-four facilities $(62 \%)$ indicated that they provided secure bicycle parking, but only 33 (46\%) provided appropriate facilities for those needing to shower and change after engaging in active transport. Only seven (10\%) actively encouraged patients and staff to walk or cycle and $31(44 \%)$ provided information on public transport. Fourteen facilities $(20 \%)$ offered 
patients shared transport services (minibus or car), while $6(8 \%)$ provided staff car pool/car share options.

Only 19 centres $(27 \%)$ reported regular use of teleconferencing to replace staff meetings, while $26(37 \%)$ reported occasional ad hoc use. Similarly, only $13(18 \%)$ used tele- or videoconferencing to replace patient clinic visits.

\section{Procurement practices}

Less than half of facilities ( $n=28 ; 39 \%$ ) believed environmental sustainability was considered in procurement decisions. A number of facilities $(n=13 ; 18 \%)$ commented on their lack of ability to control procurement due to constraints applied by their health service and/or Health Purchasing Victoria.

\section{Paper}

Twenty-nine facilities $(41 \%)$ indicated use of either virgin copy paper (i.e. paper containing no recycled content) or were unaware of the type of paper used. Eighteen facilities $(25 \%)$ had printers set for single-sided printing and $17(23 \%)$ made no effort to actively discourage printing. While approximately half of all facilities reported use of electronic medical records ( $n=33,46 \%$ ), the majority commented that these only partially replaced paper files. Automatic hand dryers were used in clinical areas in two $(3 \%)$ facilities and in public areas in $13(18 \%)$ facilities, with the remainder using paper towels for hand drying.

\section{Food}

Most facilities ( $n=54 ; 76 \%$ ) used reusable crockery/cutlery for patient meals, though only 28 (39\%) allowed pre-ordering of meals to minimise food waste. There was limited awareness among facilities of food sourcing, 'food miles' or methods of food disposal, with most facilities answering 'don't know' to these questions.

\section{Home therapies}

Six home therapy facilities (46\%) indicated that some of their patients (typically $1-25 \%$ ) recycled $\mathrm{RO}$ reject water for alternative domestic use, while only $3(23 \%)$ had any patients using renewable energy (from e.g. solar panels). Only one facility $(8 \%)$ formally supported home haemodialysis patients to establish $\mathrm{RO}$ reject water recapture or alternative power generation. Five of thirteen home therapy units $(38 \%)$ offered PVC and cardboard box 
recycling to their peritoneal dialysis patients, although this option was only available to those living in metropolitan areas. Most respondents believed that companies supplying consumables to home patients should take more responsibility for their recycling.

\section{Climate change preparedness}

Only 32 facilities (45\%) had policies and plans in place to address heat waves and only 28 (39\%) provided patients with information on how to look after themselves during extreme heat. Emergency strategies were in place to cover interruptions to power in 41 (58\%), to water in $36(51 \%)$, and to transportation services in $22(31 \%)$.

\section{Environmental policies, plans and initiatives}

Less than half of all services ( $n=35 ; 49 \%$ ) confirmed an environmental sustainability policy, and even then, these were predominantly focused on the health service as a whole, and not specifically on the dialysis facility. Few $(n=14 ; 20 \%)$ had ever performed an environmental sustainability audit (e.g. of energy use, water use, or waste disposal), formed an active green group $(n=14 ; 20 \%)$, or were currently undertaking a green project $(n=8 ; 11 \%)$. While a majority ( $n=50 ; 70 \%$ ) believed their colleagues to be supportive of green initiatives, only 35 (49\%) felt supported by their clinical director and 29 (41\%) by senior nursing colleagues. Only 15 facilities (21\%) made any formal effort (e.g. via 'in service' presentations) to raise awareness of environmental sustainability.

\section{Discussion}

This survey provides an environmental practice baseline for Victorian dialysis facilities and identifies targets for attention. It therefore represents an early step towards environmentally sustainable dialysis delivery in Australia.

It showed that limited environmentally sustainable infrastructure currently exists within dialysis buildings; for example, only $25 \%$ of facilities conserve reverse osmosis reject water for use elsewhere. Improvements to infrastructure are likely to significantly improve the CFP of dialysis facilities in Victoria. They also have the potential to generate cost savings over time, although return on investment will depend on initial capital expenditure and ongoing utility costs. Illustrating the benefits possible from incorporating RO reject water-saving methodology into a new dialysis unit build, one UK dialysis service described a recouping of implementation costs within a few months of unit opening, with recurrent savings of up to 4,492,000 litres of water and 10,558 GBP/year thereafter (10). UK and Australian data have also shown that retrofitting water-conserving equipment to existing $\mathrm{RO}$ systems can be 
financially viable and even profitable (10-13), although this will be influenced by ease of installing pipe-work and storage tanks in existing buildings and opportunities for reject waster reuse (13).

The survey also examined waste management in dialysis facilities. It found that while the majority of facilities felt they performed well with appropriately segregating waste into the three main waste streams (general waste, clinical waste and recycling), only a limited number audited waste or educated staff about appropriate waste management. Suggesting a potential lack of knowledge in this area, over a third of facilities indicated that they were able to recycle soft plastics other than PVC, despite the fact that most waste disposal companies do not support this practice. Recycling is important because it reduces resource use and burden on scarce community landfill sites. Appropriate segregation of clinical waste minimises the need for incineration and/or chemical disinfection prior to waste disposal, both of which entail significant financial and environmental cost (14). In working towards optimal waste management, dialysis facilities could consider regular auditing of waste so that objective information is available about baseline practice and improvements. Improvements will also require regular staff education around appropriate waste segregation at source, and the opportunities for, and benefits of, recycling.

The majority of dialysis patients in Australia receive facility based HD, which mandates thrice weekly travel to and from their local healthcare facility. Thus, unsurprisingly travel contributes significantly to the CFP of dialysis in Australia (6). The survey suggested that few dialysis services are actively attempting to address transport-related emissions. While success in this area will depend on the geographical location of each particular dialysis facility, all services have the potential to gain from informing patients and staff of the environmental and health benefits of active transport (cycling, walking and public transport). To encourage these practices, secure bike facilities, shower and changing areas could be considered, as could one-way patient transport options for patients wishing to walk to dialysis but unable to get home the same way due to post-dialysis fatigue (15). As telemedicine technologies in other patient populations have reportedly reduced costs, travel time and travel emissions while maintaining or improving the patient experience (16-18), renal facilities might also consider greater use of these technologies.

While energy efficiency, water and waste management and transportation are important, one report from the UK showed that $57 \%$ of the carbon emissions from healthcare derive from manufacturing and procurement of pharmaceuticals and medical equipment (19). Similarly, 
an Australian study from Barwon Health, Victoria, estimated that procurement accounted for $61.6 \%$ of the CFP of a satellite dialysis unit, in contrast to $18.6 \%$ for electricity usage, $8.8 \%$ for patient and staff travel and $7.6 \%$ for water usage (see Figure 1) (6). Meaningful efforts to reduce the dialysis sector CFP must therefore address procurement. The survey results suggested that little consideration is currently given to environmental sustainability in procurement within dialysis facilities. This supports a need for incorporation of measureable sustainability criteria into procurement contracts, relating to both the environmental impact of product manufacture and disposal and organisational environmental performance. If appropriately weighted, these criteria might stimulate more competition in this field and at the same time send a clear message to industry that environmental sustainability is a dialysis community priority.

The frequency of extreme weather is predicted to increase in coming decades due to climate change (20). Whilst this presents a threat, it may also present opportunities (21). Unfortunately, however, the survey showed only limited climate change preparedness across Victorian dialysis facilities. Effective climate change adaptation requires that the dialysis community develops and regularly reviews fire, flood and heat disaster plans. These need to include pre-disaster identification of partner dialysis facilities able to accommodate evacuees and robust methods for contacting and transporting patients prior to and during disasters. Dialysis services located in vulnerable regions might consider ongoing education of patients about the importance of evacuating early and appropriate fluid and dietary restrictions in case dialysis is unavailable. Each patient would ideally have a personal evacuation plan and an emergency supply kit pre-prepared.

Lastly, while a service-wide 'green culture' is essential if a transition to an environmentally sustainable dialysis sector is to occur, the survey results suggested this does not yet exist. To facilitate this, units could consider identifying 'green champions', making sustainability a standing agenda item at unit meetings, and incorporating sustainability training into staff orientation and professional development programs. In addition, systems could be developed to encourage both staff and patients to suggest and action green improvement initiatives.

Compromises were inevitable in the design of the survey. Whilst we sought sufficient highquality data, it was also essential that the questionnaire remained user-friendly and minimally burdensome for respondents. Moreover, a number of questions called for subjective responses, for instance, asking for an estimation of how well waste was segregated rather than requesting objective measurements of waste bin contamination. The lack of quantitative 
data in many areas limits our ability to use the survey to monitor progress, but as future auditing and objective monitoring of environmental indicators improve, the ability to request more quantitative data, and thereby to track progress, will hopefully also increase. A further issue relates to the fact that respondents were not required to answer all questions. It is possible that those with greater knowledge and/or enthusiasm about environmental issues submitted a higher proportion of responses, which may have influenced the survey results.

\section{Conclusions}

Despite these limitations, this survey provides a starting point for practice and culture change across dialysis services in Victoria. We hope it will lead dialysis staff to consider the impact of their daily practice on the environment and possible actions they might take to improve the CFP of their services (a list of suggestions is provided in Table 1). In so doing, they will not only be contributing to the long-term sustainability of our healthcare system, but also a healthy environment for current and future generations.

\section{ACKNOWLEDGEMENTS}

The GREENS survey was modelled on a similar survey sent to dialysis services in England, Scotland and Wales at the inception of the UK Green Nephrology initiative in 2009 (15). The authors would like to acknowledge the very important and ground-breaking work of the UK group in the field of 'Green Nephrology'. We would also like to acknowledge the Victorian Renal Clinical Network Nephrology Environmental Sustainability Special Interest Group (ESSIG) who developed the GREENS survey, and all of the Victorian dialysis facilities who put aside time to complete it. 


\section{REFERENCES}

1. Costello A, Abbas M, Allen A, Ball S, Bell S, Bellamy R, et al. Managing the health effects of climate change: Lancet and University College London Institute for Global Health Commission. Lancet. 2009;373(9676):1693-733.

2. UK NHS Sustainable Development Unit. July 2016. Available at URL: http://www.sduhealth.org.uk/policy-strategy/reporting/nhs-carbon-footprint.aspx. (Accessed Feb 1, 2017).

3. Chung JW, Meltzer DO. Estimate of the carbon footprint of the US health care sector. JAMA. 2009;302(18):1970-2.

4. McGain F. Sustainable hospitals? An Australian perspective. Perspect Public Health. 2010;130(1):19-20.

5. $\quad$ Agar JW. Green Dialysis: The Environmental Challenges Ahead. Semin Dial. 2014.

6. Lim AE, Perkins A, Agar JW. The carbon footprint of an Australian satellite haemodialysis unit. Aust Health Rev. 2013;37(3):369-74.

7. Brown LH, Buettner PG, Canyon DV. The energy burden and environmental impact of health services. Am J Public Health. 2012;102(12):e76-82.

8. Cass A, Chadban S, Gallagher $M$ et al. The economic impact of end-stage kidney disease in Australia: Projections to 2020. Kidney Health Australia, Melbourne, Australia; 2010.

9. Department of Health and Human Services. Renal directions: Better services and improved

kidney health for Victorians. May 22, 2013. Available at URL:

https://www2.health.vic.gov.au/getfile/?sc itemid=\{7FF3374C-7301-402F-8E9D-

2100D6B66280\}\&title=Renal\%20directions (accessed October 1, 2016).

10. Connor A, Milne S, Owen A, Boyle G, Mortimer F, Stevens P. Toward greener dialysis: a case study to illustrate and encourage the salvage of reject water. J Ren Care. 2010;36(2):68-72.

11. Ponson L, Arkouche W, Laville M. Toward green dialysis: focus on water savings. Hemodial Int. 2014;18(1):7-14.

12. Agar JW, Simmonds RE, Knight R, Somerville CA. Using water wisely: New, affordable, and essential water conservation practices for facility and home hemodialysis. Hemodial Int. 2009;13(1):32-7.

13. North West Dialysis Service (Melbourne Health). Handbook for Reusing or Recycling Reverse Osmosis Reject Water from Haemodialysis in Healthcare Facilities. Available at URL: https://www.clearwater.asn.au/user-data/research-projects/swf-files/62r-2056handbook.pdf (accessed Oct 3, 2017).

14. Hoenich NA, Levin R, Pearce C. Clinical waste generation from renal units: implications and solutions. Semin Dial. 2005;18(5):396-400.

15. Connor A, Mortimer $F$. The green nephrology survey of sustainability in renal units in England, Scotland and Wales. J Ren Care. 2010;36(3):153-60.

16. Lin MH, Yuan WL, Huang TC, Zhang HF, Mai JT, Wang JF. The clinical effectiveness of telemedicine for chronic heart failure: A systematic review and meta-analysis. Minerva Med. 2016.

17. Su D, Zhou J, Kelley MS, Michaud TL, Siahpush M, Kim J, et al. Does telemedicine improve treatment outcomes for diabetes? A meta-analysis of results from 55 randomized controlled trials. Diabetes Res Clin Pract. 2016;116:136-48.

18. Lee CJ, Park S. The Role of Home Blood Pressure Telemonitoring for Blood Pressure Control. Pulse (Basel). 2016;4(2-3):78-84.

19. UK NHS Sustainable Development Unit. Carbon Footprint update for the NHS in England. 2016. Available at URL: http://www.sduhealth.org.uk/policy-strategy/reporting/nhscarbon-footprint.aspx (accessed Mar 3, 2017). 
20. Intergovernmental Panel on Climate Change. Fifth Assessment Report. Summary for Policy Makers + Longer Report. https://www.ipcc.ch/pdf/assessment-

report/ar5/syr/SYR AR5 FINAL full wcover.pdf.

21. Barraclough KA, Blashki GA, Holt SG, Agar JWM. Climate change and kidney disease-threats and opportunities. Kidney Int. 2017;92(3):526-30.

21. Barraclough KA. Blashki GA, Holt SG, Agar JWM. Climate change and kidney diseasethreats and opportunities. Kidney International (2017);92:526-30.

This article is protected by copyright. All rights reserved. 
Figure 1: Breakdown of the carbon footprint of an Australian satellite haemodialysis unit. Adapted with permission from reference 6. Procurement (other) includes paper, food, diagnostics (pathology), sanitation products and laundry services.

This article is protected by copyright. All rights reserved. 
Table 1: Opportunities available to dialysis facilities to improve environmental sustainability

\begin{tabular}{|c|c|}
\hline Lighting & $\begin{array}{l}\text { Consider conversion to low-energy light bulbs; encourage staff to turn off lighting when } \\
\text { not in use; install motion sensors in low traffic areas }\end{array}$ \\
\hline Equipment & $\begin{array}{l}\text { Ensure computers and photocopiers are auto-configured to enter hibernation, sleep or } \\
\text { standby mode when not in use; encourage staff to log off and switch off computers when } \\
\text { not in use }\end{array}$ \\
\hline Heating \& cooling & $\begin{array}{l}\text { Ensure heating and cooling is always turned off when unit not in use; where possible, } \\
\text { ensure access to thermostats; ensure thermostats are set at appropriate temperatures }\end{array}$ \\
\hline Energy & $\begin{array}{l}\text { Seek a green electricity provider (http://greenelectricityguide.org.au) if this is not set by } \\
\text { your organisation; consider renewable energy generation }\end{array}$ \\
\hline Water & $\begin{array}{l}\text { Consider recovery and reuse of RO reject water (refer to the RO reject water handbook- } \\
\text { https://www.clearwater.asn.au/user-data/research-projects/swf-files/62r-2056- } \\
\text { handbook.pdf); investigate the cost of, and water savings from, the installation of water } \\
\text { saving taps }\end{array}$ \\
\hline Waste & $\begin{array}{l}\text { Ensure general, clinical waste and recycling bins are available and appropriately sited; } \\
\text { create posters that correctly identify appropriate waste bins; undertake regular waste } \\
\text { audits; incorporate waste education in staff induction and ongoing education programs; } \\
\text { consider PVC recycling (http://www.vinyl.org.au/pvc-in-healthcare-2/pvc-recycling-in- } \\
\text { hospitals); request that dialysis product suppliers retrieve pallets and cardboard boxes } \\
\text { on delivery }\end{array}$ \\
\hline Procurement & $\begin{array}{l}\text { Work with the person/department responsible for procurement in your facility and HPV to } \\
\text { raise ES weightings in procurement decisions; voice your opinions about issues with } \\
\text { procurement e.g. Can recycled paper be available for purchase at a reasonable cost? } \\
\text { Do suppliers retrieve packaging and pallets after delivery? }\end{array}$ \\
\hline Paper & $\begin{array}{l}\text { Discourage and monitor printing/photocopying; set up 'follow-me' printing; set } \\
\text { printers/photocopiers to double sided; consider other options for reducing paper usage } \\
\text { (e.g. using email for letters and other documents where possible); purchase recycled or } \\
\text { sustainably-sourced paper }\end{array}$ \\
\hline Transport & $\begin{array}{l}\text { Promote the health benefits of active transport to patients and staff; advocate for } \\
\text { adequate facilities for those choosing to cycle or walk; provide incentives to those } \\
\text { engaging in active transport (e.g. 'ride to work' breakfasts); provide information on public } \\
\text { transport options; investigate and encourage shared transport options; consider } \\
\text { opportunities to expand use of telehealth }\end{array}$ \\
\hline
\end{tabular}

This article is protected by copyright. All rights reserved. 


\begin{tabular}{|l|l|}
\hline Food & $\begin{array}{l}\text { Reconsider the need to provide food during dialysis; ensure use of reusable } \\
\text { crockery/cutlery for patients and staff; consider pre-ordering of patient meals }\end{array}$ \\
\hline $\begin{array}{l}\text { Climate change } \\
\text { preparedness }\end{array}$ & $\begin{array}{l}\text { Educate staff and patients about the health impacts of heat waves/floods/bushfires and } \\
\text { their potential impact on provision of dialysis and other medical care; ensure patients \& } \\
\text { the unit have emergency strategies in place for these events }\end{array}$ \\
\hline plans \& initiatives & $\begin{array}{l}\text { Identify the Health Service ES officer if your Health Service has one; identify 'Green } \\
\text { Champions' or a local 'Green Group'; nominate the Green Champion for Health Service } \\
\text { ES Committee membership; include environmental sustainability as a standing agenda } \\
\text { item for unit meetings; encourage staff and patients to propose ES improvement ideas; } \\
\text { incorporate ES education into unit meetings; advocate for incentives that encourage the } \\
\text { development and implementation of green improvement activities. }\end{array}$ \\
\hline
\end{tabular}

ES = environmental sustainability; HPV = Health Purchasing Victoria; RO = reverse osmosis;

$\mathrm{PVC}=$ polyvinyl chloride. 


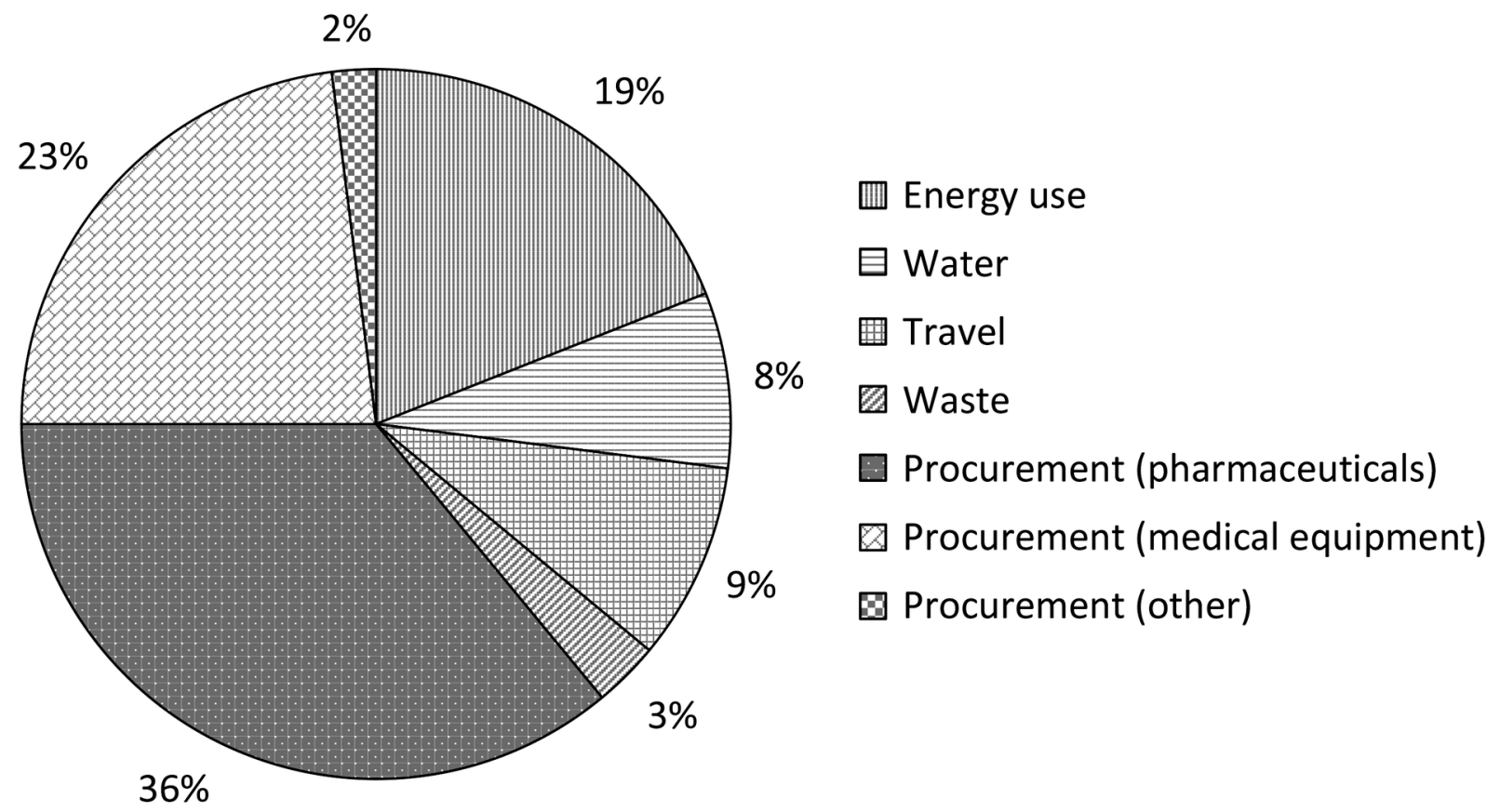

Fig 1-Barraclough2-1.tiff

This article is protected by copyright. All rights reserved. 


\section{University Library}

\section{- M M N E R VA A gateway to Melbourne's research publications}

Minerva Access is the Institutional Repository of The University of Melbourne

Author/s:

Barraclough, KA;Gleeson, A;Holt, SG;Agar, JWM

Title:

Green dialysis survey: Establishing a baseline for environmental sustainability across dialysis facilities in Victoria, Australia

Date:

2019-01-01

Citation:

Barraclough, K. A., Gleeson, A., Holt, S. G. \& Agar, J. W. M. (2019). Green dialysis survey: Establishing a baseline for environmental sustainability across dialysis facilities in Victoria, Australia. NEPHROLOGY, 24 (1), pp.88-93. https://doi.org/10.1111/nep.13191.

Persistent Link:

http://hdl.handle.net/11343/284904 